\title{
Obesity and Physical Inactivity: The Relevance of Reconsidering the Notion of Sedentariness
}

\author{
Jean-Philippe Chaput Angelo Tremblay \\ Division of Kinesiology, Department of Social and Preventive Medicine, Faculty of Medicine, Laval University, Québec City, QC, Canada
}

\section{Key Words}

Body weight - Energy balance - Knowledge-based work . Television viewing $\cdot$ Sleep

\section{Summary}

The population statistics of most countries of the world are indicating that industrialization and computerization have been associated with an increase in sedentariness and more recently with a significant shift from healthy weight to overweight. In general, this change in the overweight/obesity prevalence is attributed by health professionals to suboptimal diet and physical activity practices. However, recent data raised the possibility that excess weight gain might also be the outcome of changes imposed by our '24-hour', hectic lifestyle. Parallel to an increase in body weight, one has observed a reduction in sleep time and an increase in knowledge-based work (KBW) that appear as a growing necessity in a context of economic competitiveness and globalization. Sleep and cognitive work both exert a trivial effect on energy expenditure and may thus be considered as sedentary activities. However, their respective effect on energy intake is opposite. Indeed, an increase in the practice of the most sedentary activity, i.e. sleep, is associated with a hormonal profile facilitating appetite control whereas KBW appears as a stimulus favoring a significant enhancing effect on food intake. Television viewing is another example of sedentary activity that has been shown to increase the intake of high-density foods. These observations demonstrate that the modern way of living has favored a change in human activities whose impact goes well beyond what has traditionally been attributed to a lack of physical exercise. Therefore, we will need to reconsider the notion of 'sedentariness' which includes several activities having opposing effects on energy balance.

\section{Introduction}

For centuries, regular, vigorous physical activities were a necessity for humans to survive in a hostile environment where food was frequently rare. This was probably a source of fatigue, injury, and death. With the improvement of working processes, daily labor has become less energy-demanding, and this has resulted in a substantial improvement of the quality of life. Indeed, our modern world has provided numerous products and services that contribute to the comfort and wellbeing of people. This has obviously led to positive changes in some aspects of the health status and in the life expectancy of populations. In addition, it has contributed to considerable gains in labor efficiency and productivity. On the other hand, this new way of living favors some side effects which are not trivial. The current obesity epidemic is obviously the most famous of these 'side effects' but there are other, more subtle side effects, which can also exert a negative impact on health and economic productivity.

In the obesity field of investigation, physical activity has been traditionally considered as a strategy to burn calories. Accordingly, physical activity programs focusing on exercise duration have been frequently tested in obese individuals and have been found to promote mass loss to a certain extent, particularly when combined with an appropriate dietary regimen. It has recently been proposed that modern individuals should return to the subsistence efficiency (ratio of daily energy intake to energy cost of daily activities) of our ancestors, i.e. 3:1, which would imply a minimum of an additional $400 \mathrm{kcal} /$ day expenditure corresponding to about $1 \mathrm{~h}$ of aerobic activity per day [1]. This is concordant with the documented weightreducing effects of programs including substantial additional energy expenditure through exercise $[2,3]$. In particular, data from our group consistently showed that calorie for calorie, an increase in exercise intensity enhances post-exercise resting energy expenditure [4], skeletal muscle oxidative potential [5], and rates of fat oxidation [4]. It also favors a decrease

\begin{tabular}{|c|c|c|}
\hline KARGER & (c) 2009 S. Karger GmbH, Freiburg & $\begin{array}{l}\text { Angelo Tremblay, Ph.D. } \\
\text { Division of Kinesiology (PEPS) }\end{array}$ \\
\hline $\begin{array}{l}\text { Fax +49761 } 4520714 \\
\text { Information@Karger.de } \\
\text { www.karger.com }\end{array}$ & $\begin{array}{l}\text { Accessible online at: } \\
\text { www.karger.com/ofa }\end{array}$ & $\begin{array}{l}\text { Laval University } \\
\text { Québec City, G1K 7P4, QC, Canada } \\
\text { Tel. +1 } 418 \text { 656-7294, Fax -3044 } \\
\text { angelo.tremblay@kin.msp.ulaval.ca }\end{array}$ \\
\hline
\end{tabular}


in energy intake relative to expenditure in the short term [6] and a reduction in body fatness in the long term [4, 7]. Thus, physical activity is more than a calorie-burning agent. It is also a stimulus that, when properly managed, contributes to a significant improvement of energy and macronutrient balance regulation and to global body functioning, i.e. a precise regulation of body homeostasis. This is discretely expressed at many levels of regulatory processes, be it by stimulating the effect of key enzymes, by increasing the sensitivity to hormones, by facilitating substrate transport through membranes, by influencing cell receptors in a tissue-specific manner, and much more [8]. It thus seems appropriate to propose that an active lifestyle can affect energy balance and body fat to a much greater extent than what is generally perceived by health professionals. However, to reach this outcome, aerobic exercise should be performed regularly and ideally on a permanent basis.

It is a truism that the positive energy balance underlying obesity is generally attributed to factors exerting a direct, measurable impact on energy intake or expenditure. Thus, lack of physical activity and/or excess caloric intake represent the 'Big Two' factors on which almost all the attention of health professionals is devoted in preventive and therapeutic programs for obesity. However, recent research data reveal that other, less obvious factors can also promote a positive energy balance and body fat gain $[9,10]$. These nontraditional determinants of obesity do not have a direct, substantial impact on energy intake or expenditure, but rather produce a mismatch between energy input and output. For instance, our round-the-clock sedentary lifestyle that characterizes the contemporary way of living modifies the balance between physical and mental activities with the consequence that modern stimuli must now be considered as potential contributors to the obesity epidemic $[10,11]$. This is the case for short sleeping and knowledgebased work (KBW), two human practices that have emerged in the past decades. As discussed in this paper, sleep and KBW exert a negligible effect on energy expenditure and are considered as sedentary activities of the daily schedule. However, the net impact on the regulation of energy balance is not the same since an increase in KBW is orexigenic, whereas a good night's sleep facilitates appetite control and may thus be considered as a 'satiating' factor. In this context, our modern world has favored a change in human activities for which the impact goes well beyond what has been traditionally attributed to sedentariness. Accordingly, our sedentary behaviors should not only be perceived as a decrease in the amount of calories expended, and this implies that the notion of 'sedentariness' has to be reconsidered in a context of obesity prevention strategies. It is important to mention that we do not want to delineate 'sedentariness' from 'lack of physical activity' or 'physical inactivity' in the present manuscript. The main aim of this conceptual paper is to discuss the impact of modern-life sedentary behaviors on energy balance and to highlight the fact that physical inactivity may also be salutary for our health, particularly in the case of sleep.

\section{Sleep Loss: An Endemic Condition of Modern Societies}

Chronic partial sleep curtailment seems to have developed during the past few decades and has become highly prevalent. In 1960, the American Cancer Society conducted a survey study in adults [12] that found modal sleep duration to be 8.0-8.9 h. In 1995, a survey conducted by the National Sleep Foundation [13] concluded that the mean had dropped to 7 h. In 2004, more than $30 \%$ of adult men and women between the age of 30 and 64 years reported sleeping $<6 \mathrm{~h}$ per night [14]. Likewise, modern-day US adolescents do not satisfy their sleep need, and adolescents 16-18 years of age appeared to have an average sleep deficit of roughly $2 \mathrm{~h}$ during the week [15].

Lack of sleep has become a widespread habit driven by the demands and opportunities of our turbulent lifestyle. The causes of sleep loss include, but are not limited to, occupational factors, such as extended work schedules, jet lag, or shift work, resulting in irregular sleep patterns, and lifestyle choices, including late-night television watching, Internet use, or consumption of caffeine and/or other stimulants [16]. Additionally, common sleep disorders, such as insomnia, sleep-disordered breathing, sleep apnea, restless legs syndrome, narcolepsy, and circadian rhythm disorders, can cause sleep loss [17]. Sleep disorders and sleep loss are associated with mental distress, depression, anxiety, obesity, hypertension, diabetes, high cholesterol levels, and adverse health behaviors such as cigarette smoking, physical inactivity, and heavy drinking [17-22]. Thus, sleep loss is an under-recognized public health problem that has a cumulative effect on physical and mental health.

Physiological data suggest that short-term partial sleep restriction leads to striking alterations in metabolic and endocrine functions, including decreased carbohydrate tolerance, insulin resistance, increased sympathetic tone, elevated cortisol concentrations, elevated levels of pro-inflammatory cytokines, and decreased leptin and increased ghrelin levels [2326]. Furthermore, abnormal sleep-wake patterns likely alter intracellular circadian clocks that may potentiate disrupted metabolism and weight gain [27]. Thus, one could speculate that chronic lack of sleep represents a stress factor stimulating appetite, promoting weight gain, and impairing glycemic regulation, with a subsequently increased risk of type 2 diabetes. The potential mechanisms by which sleep deprivation may predispose to obesity are shown in figure 1 .

\section{Impact of Sleep on Energy Balance}

The positive impact of a good night's sleep is well demonstrated. From a physiological standpoint, it has been known for several decades that sleep exerts profound modulatory effects on hormones and metabolism. For instance, the secretion of growth hormone $(\mathrm{GH})$ and prolactin is markedly increased during sleep, whereas the release of cortisol and thyrotropin 


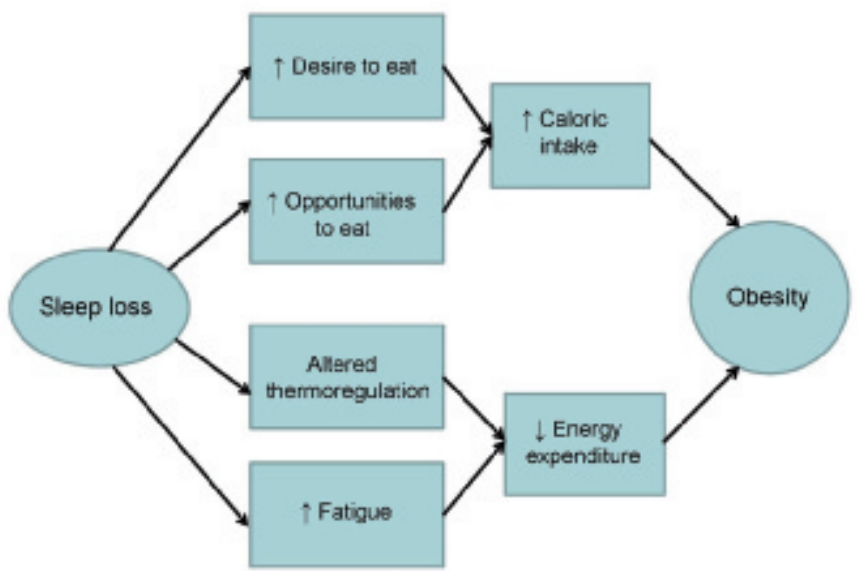

Fig. 1. Potential mechanisms by which sleep loss may predispose to obesity. Adapted from Patel and $\mathrm{Hu}[32]$.

(TSH) is inhibited [23, 28]. In addition, decreased core body temperature, decreased heart rate, decreased blood pressure, decreased sympathetic nerve activity, increased vagal tone, and decreased cerebral glucose utilization are all observed during sleep [23, 28]. Hence, the beneficial effects of sleep go well beyond its role in the restoration and maintenance of tissue structure and function.

Sleep is the most sedentary of human activities. Its energy cost is about $1 \mathrm{kcal} / \mathrm{min}$ in adults of normal body mass, and slightly more after gain of weight [29]. Despite the low energy cost of sleep, population studies have repeatedly shown that a short average duration of sleep is associated with excess body weight [25, 30-34]. Furthermore, short sleeping hours in children have been shown to predict overweight or obesity to a greater extent than does low physical activity participation and long television viewing [35], and to preferentially favor abdominal adiposity [36]. As mentioned above, the most plausible explanation to date as to why short sleep duration impacts body weight is an alteration of the neurohormonal profile characterized by an increase in the orexigenic hormone ghrelin and a decrease in the anorexigenic hormone leptin $[24,25,33]$. Conversely, a good night's sleep is expected to favor an optimal hormonal milieu for body homeostasis, and recent research evidence showed that an average nightly sleep of 7-8 $\mathrm{h}$ in adults is associated with a lower risk of obesity [25, $34]$, type 2 diabetes [37, 38], coronary heart disease [39], and all-cause mortality [40].

Although a U-shaped association between sleep and health indicators has been observed in some studies, it is important to mention that the two peaks do not mean the same thing. Indeed, no studies to date have demonstrated a possible mechanism identifying long sleep as a cause of mortality or morbidity, including obesity [41]. Recent results suggest that depressive symptoms are a strong predictor of long sleep, and, due to their high prevalence, they are the most likely confounder of the association between long sleep and mortality risk [42]. There is evidence, however, for mecha- nisms linking short sleep to morbidity, and short sleep is much more common in our society than long sleep [41]. Furthermore, some have argued that long sleepers are spending a lot of time in bed but are not getting a lot of sleep, i.e. they might have poor sleep quality possibly due to sleep disorders or other health issues. It is thus not clear that sleeping $9 \mathrm{~h}$ or more is inherently dangerous, particularly for a healthy individual.

In summary, sleep is probably the most sedentary of all activities regarding its impact on energy expenditure. However, an increase in the time allocated to this low-calorie-burning activity should not be negatively perceived given the beneficial impact of sleep on the regulation of energy balance. Indeed, a good night's sleep is expected to favor a good matching between energy input and output, thus preventing weight gain.

\section{Knowledge-Based Work: A Growing Necessity in a Context of Modernity}

Another important change in human activity that has recently occurred, particularly since the large availability of computers, is an increase in mental activity. Indeed, globalization and technological changes have favored a progressive switch from physically demanding tasks to KBW soliciting an enhancing cognitive demand [43]. For children, this may be reflected by an increase in computer 'chatting', whereas for adults, this may rather represent an increase in KBW that appears as a growing necessity in a context of economic competitiveness. Of course, this transition to a modern world has contributed to the comfort and well-being of individuals and to considerable gains in labor efficiency and productivity. This transition to a modern world has also redefined the notion of fatigue, which becomes more and more a 'burnout' of psychosomatic nature rather than representing physical exhaustion [44].

From a physiological standpoint, the biological requirements of physical and mental work are not the same. Indeed, physical activity solicits skeletal muscle metabolism that relies on fat metabolism to a significant extent, as opposed to KBW which is a type of activity that relies on the brain which essentially utilizes glucose for its metabolism under normal feeding conditions [45]. Furthermore, if one considers that free fatty acids cannot be converted to glucose, this means that KBW essentially relies on the small body carbohydrate stores and on carbohydrate intake. Thus, this switch in the macronutrient oxidation profile can be realistically considered as a potential cause of the suspected effects of KBW on energy intake. This expected effect is concordant with the glucostatic theory of appetite control [46] which stipulates that variations in one or several variables related to carbohydrate metabolism can be sensed by the brain, which could affect food intake. 
Fig. 2. Cortisolemia observed while performing a reading-writing activity for $45 \mathrm{~min}$ and spontaneous energy intake in an ad libitum meal following the task in female students categorized by their degree of mental workload. Note: A long reaction time reflects a high perceived mental workload. Data are expressed as mean \pm SD. *Significantly different from students presenting a short reaction time, $\mathrm{p}<0.05$. Adapted from Chaput et al. [47].

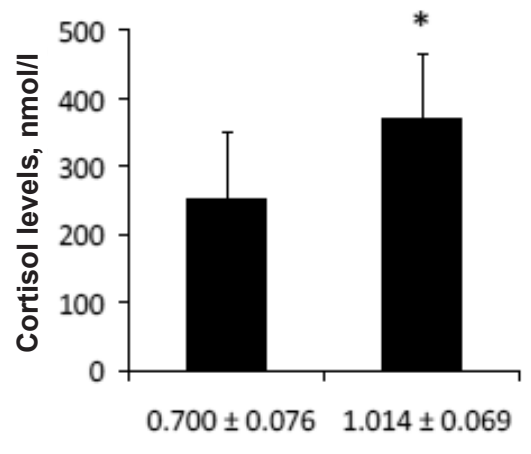

Reaction time, $s$

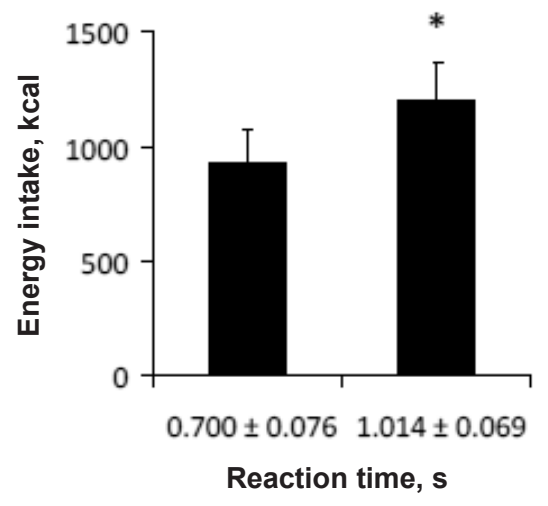

\section{Impact of Knowledge-Based Work on Energy Balance}

The assumption that KBW might significantly increase energy intake due to its dependence on glucose availability was first tested in the context of a case study [8] in which the participant reported a substantial increase in hunger and displayed plasma glucose instability while preparing a grant application. More recently, the testing of female Laval University students confirmed that KBW increases plasma glucose instability and induces a significant increase in spontaneous energy intake [47]. Interestingly, we observed in the latter study that mental work solicited by computer-related activities produced an increase in cortisol levels which was related to a compensatory increase in energy intake, as shown in figure 2. This hyperphagic effect of KBW agrees with the results of a study involving scientists from the University of Washington [48] who increased their energy and fat intake at the time of the preparation of NIH (National Institutes of Health) grant applications. In addition, the fluctuations in plasma glucose levels that were observed in these two studies agree with literature showing that a period of intense cognitive processing leads to a measurable decrease in levels of blood glucose [49]. This fall in blood glucose has also been associated with feeling less energetic [50] whereas higher blood glucose levels that are within the normal range have been associated with lower self-reported tension and greater energy [51]. Accordingly, food intake might be perceived as a strategy for allowing the individual to recover optimal body functioning.

In another study [52], female students were subjected to two randomly assigned 45-min sessions during which mental work (reading-writing) or rest were performed. As expected, the accomplishment of the mental task had only a trivial impact on energy expenditure, which increased by $3 \mathrm{kcal}$ over $45 \mathrm{~min}$ compared with the resting condition. This is concordant with the demonstration that mental effort requires an insignificant additional energy expenditure, which has been reported some decades ago [53-55]. Conversely, the effect of mental work on ad libitum energy intake in a buffet-type meal was striking, since it exceeded the intake measured during the meal following the rest condition by $229 \mathrm{kcal}$. This raises the possibility that KBW adds a new component to sedentariness that might further accentuate the positive energy balance that is more likely to occur when one is inactive. Interestingly, the overconsumption of food was observed without increased feelings of hunger, as previously reported [47]. This gap between appetite sensations and spontaneous energy intake could be explained by the fact that KBW impairs satiety signal capacity [47].

It may be somewhat paradoxical that the amount of $\mathrm{KBW}$ is more important in the higher socioeconomic groups but results in a higher prevalence of obesity for the socioeconomically disadvantaged [56]. However, we need to look at the obesity epidemic in a wider context if we want to understand its etiology. Obesity is a very complex condition with numerous determinants interacting together and showing large interindividual variations. Thus, individuals highly involved in KBW are not all prone to overeat, and short sleepers are not all obese. On the other hand, data showed that short sleeping and KBW are two stimuli entraining a mismatch between energy input and output. This observation must be taken into account when it is time to address the obesity problem. Hopefully, other healthy behaviors such as regular physical activity may counterbalance the net impact of these stimuli on energy balance.

In addition, it raises the question as to whether other sedentary leisure activities such as video game playing or chatting on the Internet, having gained a lot of popularity especially in children, are also hyperphagic stimuli like KBW. It has been recently reviewed that television and other electronic media have changed the life of children fundamentally and influence children's mental and somatic well-being negatively [57]. Furthermore, exposure to mass media (television, movies, magazines, Internet) has been shown to be correlated with obesity and negative body image, which may lead to overeating [58]. Recent data also showed that watching television increases the intake of high-density, palatable, familiar foods and may constitute a vector contributing to the current obesity crisis [59]. Some data also underscore the importance of tackling socioeconomic differences. Indeed, a large cross-national study in adolescents [60] found that those most likely to watch television are boys of lower socioeconomic status. Likewise, data from a nationally representative sample of adults in the 
United States [61] showed that television viewing was associated with having a high school education or less, living in a household with income below $131 \%$ of the federal poverty level, and not being employed. These issues are of growing relevance since population statistics reveal that children watch television an average of 3-4.5 h per day [62]. More importantly, a recent report suggests that most television viewing by children is carried out at or near bedtime [63], and television viewing has been reported to adversely affect sleep [64].

\section{Conclusion}

As discussed in this paper, the notion of 'sedentariness' includes several activities that possess a low caloric cost. However, the net impact of these low-calorie-burning activities on energy balance has been disregarded up to now as these activities have always been viewed in terms of their impact on energy expenditure. In light of the growing body of evi- dence pertaining to the effects of sleep and cognitive work on energy balance regulation, it appears evident that these two modalities of human activity exert opposing effects on energy intake. Hence, we will need to reconsider the notion of 'sedentariness' in a context of obesity prevention strategies since the impact of several sedentary activities on energy balance is very variable.

\section{Acknowledgements}

JPC is supported by a studentship from the Hôpital Laval Research Center and AT is partly funded by the Canada Research Chair in Environment and Energy Balance.

\section{Disclosure}

There is no conflict of interest to declare.

\section{References}

1 Cordain L, Gotshall RW, Eaton SB: Physical activity, energy expenditure and fitness: an evolutionary perspective. Int J Sports Med 1998;19:328-335.

$>2$ Woo R, Garrow JS, Pi-Sunyer FX: Voluntary food intake during prolonged exercise in obese women. Am J Clin Nutr 1982;36:478-484.

3 Gwinup G: Effect of exercise alone on the weight of obese women. Arch Intern Med 1975;135:676-680.

$\checkmark 4$ Yoshioka M, Doucet E, St-Pierre S, Alméras N, Richard D, Labrie A, Després JP, Bouchard C, Tremblay A: Impact of high-intensity exercise on energy expenditure, lipid oxidation and body fatness. Int $\mathbf{J}$ Obes Relat Metab Disord 2001;25:332-339.

5 Tremblay A, Simoneau JA, Bouchard C: Impact of exercise intensity on body fatness and skeletal muscle metabolism. Metabolism 1994;43:814-818.

6 Imbeault P, Saint-Pierre S, Alméras N, Tremblay A: Acute effects of exercise on energy intake and feeding behaviour. Br J Nutr 1997;77:511-521.

7 Tremblay A, Després JP, Leblanc C, Craig CL, Ferris B, Stephens T, Bouchard C: Effect of intensity of physical activity on body fatness and fat distribution. Am J Clin Nutr 1990;51:153-157.

$>8$ Tremblay A, Therrien F: Physical activity and body functionality: implications for obesity prevention and treatment. Can J Physiol Pharmacol 2006;84: 149-156.

9 Keith SW, Redden DT, Katzmarzyk PT, Boggiano MM, Hanlon EC, Benca RM, Ruden D, Pietrobelli A, Barger JL, Fontaine KR, Wang C, Aronne LJ, Wright SM, Baskin M, Dhurandhar NV, Lijoi MC, Grilo CM, DeLuca M, Westfall AO, Allison DB: Putative contributors to the secular increase in obesity: exploring the roads less traveled. Int J Obes (Lond) 2006;30:1585-1594.

10 Tremblay A, Chaput JP: About unsuspected potential determinants of obesity. Appl Physiol Nutr Metab 2008;33:791-796.

11 Kappos AD: The impact of electronic media on mental and somatic children's health. Int J Hyg Environ Health 2007;210:555-562.
12 Kripke D, Simons R, Garkinkel L, Hammond E: Short and long sleep and sleeping pills. Is increased mortality associated? Arch Gen Psychiatry 1979;36: 103-116.

13 Gallup Organization: Sleep in America. Princeton, NJ, Gallup Organization, 1995.

14 National Center for Health Statistics: QuickStats: Percentage of Adults who Reported an Average of $\leq 6 \mathrm{~h}$ of Sleep per 24-Hour Period, by Sex and Age Group - United States, 1985 and 2004. Morbidity and Mortality Weekly Report, 2005.

15 National Sleep Foundation: 2006 'Sleep in America' poll. National Sleep Foundation. Washington, D.C. www.sleepfoundation.org/site/c.huIXKjM0IxF/ b.2417141/k.2E30/The_National_Sleep_Foundation. htm.

16 Chokroverty S (ed): Sleep Disorders Medicine: Basic Science, Technical Considerations, and Clinical Aspects, ed 2. Boston, MA, Butterworth and Heinemann, 1999, pp 14-16.

17 Institute of Medicine: Sleep Disorders and Sleep Deprivation: An Unmet Public Health Problem. Washington, DC, The National Academies Press, 2006. www.iom.edu/cms/3740/23160/33668.aspx.

18 Strine TW, Chapman DP: Associations of frequent sleep insufficiency with health-related quality of life and health behaviors. Sleep Med 2005;6:23-27.

19 Chaput JP, Després JP, Bouchard C, Tremblay A: Association of sleep duration with type 2 diabetes and impaired glucose tolerance. Diabetologia 2007; 50:2298-2304.

20 Cappuccio FP, Taggart FM, Kandala NB, Currie A, Peile E, Stranges S, Miller MA: Meta-analysis of short sleep duration and obesity in children and adults. Sleep 2008;31:619-626.

21 Choi KM, Lee JS, Park HS, Baik SH, Choi DS, Kim SM: Relationship between sleep duration and the metabolic syndrome: Korean National Health and Nutrition Survey 2001. Int J Obes (Lond) 2008;32: 1091-1097.
22 Gangwisch JE, Heymsfield SB, Boden-Albala B Buijs RM, Kreier F, Pickering TG, Rundle AG, Zammit GK, Malaspina D: Short sleep duration as a risk factor for hypertension: analyses of the first National Health and Nutrition Examination Survey. Hypertension 2006;47:833-839.

23 Spiegel K, Leproult R, Van Cauter E: Impact of sleep debt on metabolic and endocrine function. Lancet 1999;354:1435-1439.

24 Spiegel K, Tasali E, Penev P, Van Cauter E: Brief communication: sleep curtailment in healthy young men is associated with decreased leptin levels, elevated ghrelin levels, and increased hunger and appetite. Ann Intern Med 2004;141:846-850.

25 Taheri S, Lin L, Austin D, Young T, Mignot E: Short sleep duration is associated with reduced leptin, elevated ghrelin, and increased body mass index. PLoS Med 2004;1:210-217.

26 Vgontzas AN, Papanicolaou DA, Bixler EO, Hopper K, Lotsikas A, Lin HM, Kales A, Chrousos GP: Sleep apnea and daytime sleepiness and fatigue: relation to visceral obesity, insulin resistance, and hypercytokinemia. J Clin Endocrinol Metab 2000; 85:1151-1158.

27 Bray MS, Young ME: Circadian rhythms in the development of obesity: potential role for the circadian clock within the adipocyte. Obes Rev 2006; 8:169-181.

28 Van Cauter E, Holmbäck U, Knutson K, Leproult R, Miller A, Nedeltcheva A, Pannain S, Penev P, Tasali E, Spiegel K: Impact of sleep and sleep loss on neuroendocrine and metabolic function. Horm Res 2007;67(suppl 1):2-9.

29 Tremblay MS, Esliger DW, Tremblay A, Colley R: Incidental movement, lifestyle-embedded activity and sleep: new frontiers in physical activity assessment. Appl Physiol Nutr Metab 2007;32(suppl 2): S208-S217.

30 Hasler G, Buysse DJ, Klaghofer R, Gamma A, Ajdacic V, Eich D, Rössler W, Angst J: The association between short sleep duration and obesity in young adults: a 13-year prospective study. Sleep 2004;27:661-666. 
31 Gangwisch JE, Malaspina D, Boden-Albala B, Heymsfield SB: Inadequate sleep as a risk factor for obesity: analyses of the NHANES I. Sleep 2005; 28:1289-1296.

32 Patel SR, Hu FB: Short sleep duration and weight gain: a systematic review. Obesity (Silver Spring) 2008; 16:643-653.

33 Chaput JP, Després JP, Bouchard C, Tremblay A: Short sleep duration is associated with reduced leptin levels and increased adiposity: results from the Quebec Family Study. Obesity 2007;15:253-261.

34 Chaput JP, Després JP, Bouchard C, Tremblay A: The association between sleep duration and weight gain in adults: a 6-year prospective study from the Quebec Family Study. Sleep 2008;31:517-523.

\$3 Chaput JP, Brunet M, Tremblay A: Relationship between short sleeping hours and childhood overweight/obesity: results from the 'Québec en Forme' Project. Int J Obes 2006;30:1080-1085.

36 Chaput JP, Tremblay A: Does short sleep duration favor abdominal adiposity in children? Int J Pediatr Obes 2007;2:188-191.

37 Yaggi HK, Araujo AB, McKinlay JB: Sleep duration as a risk factor for the development of type 2 diabetes. Diabetes Care 2006;29:657-661.

\38 Gangwisch JE, Heymsfield SB, Boden-Albala B, Buijs RM, Kreier F, Pickering TG, Rundle AG, Zammit GK, Malaspina D: Sleep duration as a risk factor for diabetes incidence in a large U.S. sample. Sleep 2007;30:1667-1673.

-39 Ayas NT, White DP, Manson JE, Stampfer MJ, Speizer FE, Malhotra A, Hu FB: A prospective study of sleep duration and coronary heart disease in women. Arch Intern Med 2003;163:205-209.

40 Tamakoshi A, Ohno Y; JACC Study Group: Selfreported sleep duration as a predictor of all-cause mortality: results from the JACC study, Japan. Sleep 2004;27:51-54.

41 Knutson KL, Turek FW: The U-shaped association between sleep and health: the 2 peaks do not mean the same thing. Sleep 2006;29:878-879.
42 Patel SR, Malhotra A, Gottlieb DJ, White DP, Hu FB: Correlates of long sleep duration. Sleep 2006; 29:881-889.

43 Mitter S: Globalization, technological changes and the search for a new paradigm for women's work. Gend Technol Dev 1999;3:3-17.

44 Iacovides A, Fountoulakis KN, Kaprinis S, Kaprinis G: The relationship between job stress, burnout and clinical depression. J Affect Disord 2003;75:209-221.

45 Vander AJ, Sherman JH, Luciano DS, Brière R: Physiologie Humaine, ed 3. Montreal, Chenelière/ McGraw-Hill, 1995.

46 Mayer J: Glucostatic mechanism of regulation of food intake. N Engl J Med 1953;249:13-16.

47 Chaput JP, Drapeau V, Poirier P, Teasdale N, Tremblay A: Glycemic instability and spontaneous energy intake: association with knowledge-based work. Psychosom Med 2008;70:797-804.

48 McCann BS, Warnick GR, Knopp RH: Changes in plasma lipids and dietary intake accompanying shifts in perceived workload and stress. Psychosom Med 1990;52:97-108

49 Scholey AB, Harper S, Kennedy DO: Cognitive demand and blood glucose. Physiol Behav 2001;73: 585-592.

50 Owens DS, Parker PY, Benton D: Blood glucose and subjective energy following cognitive demand. Physiol Behav 1997;62:471-478.

51 Benton D, Owens D: Is raised blood glucose associated with the relief of tension? J Psychosom Res 1993:37:1-13.

52 Chaput JP, Tremblay A: Acute effects of knowledge-based work on feeding behavior and energy intake. Physiol Behav 2007;90:66-72.

53 Benedict FG, Carpenter TM: The Influence of Muscular and Mental Work on Metabolism and the Efficiency of the Human Body as a Machine. Washington, DC, U.S. Department of Agriculture, Office of Experiment Stations, 1909, Bulletin No. 208.
54 Benedict FG, Benedict CG: The energy requirements of intense mental effort. Proc Natl Acad Sci U S A 1930;16:438-443.

55 Passmore R, Durnin JV: Human energy expenditure. Physiol Rev 1955;35:801-840.

56 McLaren L: Socioeconomic status and obesity. Epidemiol Rev 2007;29:29-48.

57 Kappos AD: The impact of electronic media on mental and somatic children's health. Int J Hyg Environ Health 2007;210:555-562.

58 Derenne JL, Beresin EV: Body image, media, and eating disorders. Acad Psychiatr 2006;30:257-261.

59 Blass EM, Anderson DR, Kirkorian HL, Pempek TA, Price I, Koleini MF: On the road to obesity: television viewing increases intake of high-density foods. Physiol Behav 2006;88:597-604.

60 Vereecken CA, Todd J, Roberts C, Mulvihill C, Maes L: Television viewing behavior and associations with food habits in different countries. Public Health Nutr 2006;9:244-250.

61 Bowman SA: Television-viewing characteristics of adults: correlations to eating practices and overweight and health status. Prev Chronic Dis 2006; 3:1-11.

62 Currie C, Roberts C, Morgan A, Smith R, Settertobulte W, Samdal O, Barnekow Rasmussen V: Young people's health in context: Health Behaviour in School-aged Children (HBSC) Study: international report from the 2001/2002 survey. Health Policy for Children and Adolescents, No. 4. World Health Organization, Copenhagen, 2004.

63 Ofcom: Child obesity - food advertising in context. 2004. www.ofcom.org.uk/research/tv/reports/food_ ads.

64 Owens J, Maxim R, McGuinn M, Nobile C, Msall M, Alario A: Television-viewing habits and sleep disturbance in school children. Pediatrics 1999;104:e27. 